\title{
Anabases
}

ANABASES Traditions et réceptions de l'Antiquité

5 | 2007

Varia

\section{Laura FOURNIER-FINOCCHIARO, Giosuè Carducci et la construction de la nation italienne}

Philippe Foro

\section{(2) OpenEdition}

Journals

Édition électronique

URL : http://journals.openedition.org/anabases/3237

DOI : $10.4000 /$ anabases.3237

ISSN : 2256-9421

Éditeur

E.R.A.S.M.E.

Édition imprimée

Date de publication : 1 mars 2007

Pagination : 264-265

ISSN : 1774-4296

Référence électronique

Philippe Foro, "Laura fournier-Finocchiaro, Giosuè Carducci et la construction de la nation italienne », Anabases [En ligne], 5 | 2007, mis en ligne le 01 janvier 2012, consulté le 22 septembre 2020. URL http://journals.openedition.org/anabases/3237 ; DOI : https://doi.org/10.4000/anabases.3237

Ce document a été généré automatiquement le 22 septembre 2020.

(c) Anabases 


\title{
Laura FOURNIER-FINOCCHIARO, Giosuè Carducci et la construction de la nation italienne
}

\author{
Philippe Foro
}

\section{RÉFÉRENCE}

Laura FOURNIER-FINOCCHIARO, Giosuè Carducci et la construction de la nation italienne, Caen, Cahiers de Transalpina, Presses universitaires de Caen, 2006, 215 p.

20 euros / ISBN 2-84133-274-8.

1 Ayant consacré sa thèse de doctorat à Giosuè Carducci, Laura Fournier-Finocchiaro nous propose un ouvrage consacré au prix Nobel de littérature de 1906, non pas sur les aspects littéraires et esthétiques mais au "poids sociologique de Carducci, c'est-à-dire sa valeur culturelle, sociale et historique, ainsi que ses aptitudes à exercer des fonctions d'organisateur culturel et de médiateur politique »(p.9). Le poète de la romanité, admiré par D'Annunzio, est né en 1835 à Val di Castello (province de Lucques). Diplômé de l'École Supérieure de Pise, il est nommé professeur de littérature italienne à l'université de Bologne en 1860 et ce jusqu'en 1904. Républicain à l'origine, il se rallie en 1878 à la monarchie des Savoie qu'il reconnait être un élément fondamental de l'unité italienne tout en se liant d'amitié avec la reine Marguerite, épouse de Humbert I . Par la suite, il soutiendra la politique nationaliste de Francesco Crispi, y compris ses entreprises coloniales qui se termineront par le désastre d'Adoua en 1896, alors même qu'il avait été beaucoup plus réticent dans les années 1880, au temps d'Agostino Depretis. Un de ses objectifs est «la recherche d'une continuité historique de la littérature italienne, héritière de la littérature gréco-latine » (p. 30) afin de nationaliser les élites italiennes par l'étude de la littérature car «l'idéal classique qui l'anime n'est pas seulement une célébration active des belles formes antiques, c'est aussi une voie et un outil pour retrouver les racines de sa patrie » (p. 39). Ainsi, la culture antique est un 
moyen de dépasser le régionalisme italien car «la valeur romaine n'est pas encore morte ", comme il l'écrit dans l'Ode à Giuseppe Garibaldi en 1859 (p. 73 ).

2 Si la première visite à Rome de Carducci ne date que de 1877 et lui donne l'occasion d'écrire Dinanzi alle terme di Caracalla (Devant les thermes de Caracalla), l'assimilation que fait le professeur bolonais entre Rome et l'Italie devient un leitmotiv de sa pensée. «Vive l'Italie, une, indivisible, éternelle comme sa mère Rome!", s'écrie-t-il dans une allocution prononcée à Pise en 1886. Il défend l'idée d'un héritage génétique de Rome vis-à-vis de l'Italie, permettant une fusion entre les deux entités, entre les Romains et les Italiens. Le patriotisme de Carducci l'amène, fort logiquement, à revendiquer le rattachement des terres irrédentes du Trentin et de l'Istrie, alors administrées par l'Autriche-Hongrie. Afin de populariser la romanité italienne, il favorise les commémorations des grandes figures de la civilisation romaine tels Virgile, les Gracques. Par contre, il rejette le modèle césarien du pouvoir, assimilé à la tyrannie que représente, à ses yeux, l'empereur Napoléon III, protecteur de Pie IX.

3 À l'image de Mazzini, parfois comparé à Caius Gracchus, Carducci croit à la formation d'une troisième Rome, populaire et anticléricale, et il participe, par ses écrits, mais non par sa présence, aux commémorations du vingt-cinquième anniversaire de l'entrée des troupes royales dans la Ville, le 20 septembre 1870. S'il valorise la Rome antique, il rejette la Rome pontificale accusée d'avoir été l'obstacle à l'unité de la nation. Aussi participe-t-il à l'élaboration du mythe de Garibaldi, nouveau Thémistocle (mais également assimilé à Miltiade, Épaminondas, Thrasybule), et farouche partisan du rattachement de Rome au royaume d'Italie. Mais l'anticléricalisme de Carducci est également lié à un choix esthétique. « Pour le poète, l'Italie est l'héritière de Rome et de la Grèce, et dans son désir d'instaurer le modèle antique comme point de repère de la société moderne, on note une certaine volonté de se défaire de la spiritualité catholique au nom d'une vision laïque et même païenne du monde » (p.153-154) à l'image de son œuvre de 1865, L'hymne à Satan. Outre l'aspect anti-catholique, la pensée de Carducci cherche aussi à fournir une religion civile aux Italiens, en parallèle à la profonde et ancienne tradition catholique.

4 Ainsi, le livre de Laura Fournier-Finocchiaro permet aux lecteurs de mieux connaitre un des grands écrivains italiens $\mathrm{du}$ xIx ${ }^{\mathrm{e}}$ siècle, dont la renommée reste néanmoins limitée de ce côté-ci des Alpes. Pour l'historien de l'Italie contemporaine, cet ouvrage participe de la réflexion sur la construction de l'idée nationale et du rôle qu'a pu y jouer la référence à l'Antiquité romaine et, de manière moins prégnante, grecque.

\section{AUTEURS}

\section{PHILIPPE FORO}

Université de Toulouse-Le Mirail

philippe.foro@wanadoo.fr 